\title{
Ethical Dilemmas of Sociability
}

\author{
KIMBERLEY BROWNLEE \\ University of Warwick
}

\begin{abstract}
There is a tension between our need for associative control and our need for social connections. This tension creates ethical dilemmas that we can call each-we dilemmas of sociability. To resolve these dilemmas, we must prioritize either negative moral rights to dissociate or positive moral rights to social inclusion. This article shows that we must prioritize positive social rights. This has implications both for personal morality and for political theory. As persons, we must attend to each other's basic social needs. As a society, we must adopt a sufficientarian approach to the regulation of social resources.
\end{abstract}

For without friends no one would choose to live, though he had all other goods ...

Aristotle, Nicomachean Ethics, book VIII

\section{INTRODUCTION}

This article is about the ethics of sociability. In my hands, the ethics of sociability includes four categories of moral concern: (1) the moral reasons and duties that we have to provide decent social contact to each other; (2) the interpersonal, social rights that we may assert; (3) the value of social inclusion; and (4) the virtues of sociability. ${ }^{1}$ This article is about (1), (2) and (3), and puts virtue aside for another day. As a set of moral concerns, the ethics of sociability has received little philosophical attention. The reasons to attend to it are ontological, normative and empirical.

Ontologically, human beings are by nature social creatures. To be a human is to be an 'obligatorily gregarious' creature, as zoologists would

1 The ethics of sociability might seem to be a branch of the ethics of care, but it is not. First, the ethics of care focuses on the moral importance of meeting the needs of the persons for whom we take responsibility; it is fundamentally about relationships. Second, the ethics of care is presented as an account of morality that competes with traditional approaches and conceptual frameworks that focus on rights, duties, justice, autonomy and practical reason. By contrast, the ethics of sociability, while it includes reflection on relationships, has a broader scope. The social rights we may assert go beyond relationship-rights; the social duties we have to be inclusive are not restricted to relationship-duties. Also, the ethics of sociability does not seek to sit at a distance from traditional moral theories. The conceptual tools of rights, duties, justice, autonomy, and reason can be incorporated fruitfully into our thinking about our social nature as human beings.

(c) Cambridge University Press 2015. This is an Open Access article, distributed under the terms of the Creative Commons Attribution licence (http://creativecommons.org/ licenses/by/3.0/), which permits unrestricted re-use, distribution, and reproduction in any medium, provided the original work is properly cited. Utilitas Vol. 28, No. 1, March 2016

doi:10.1017/S0953820815000175 
put it. ${ }^{2}$ It is to be a being who is generally found in close proximity to others of the same species, and who seeks out and needs their company in order to survive and flourish. Our social needs include basic, non-contingent needs for decent contact, inclusion, association and interdependent care - in short social connections - without which we could not lead human lives. ${ }^{3}$ Our social needs also include social contribution needs since social contribution goes as much to the heart of what it means to be human as social access does. To be human is to have a deep desire to offer our social connections to others and to have that offer be accepted. It is to desire to be needed, to be dependable, and to be depended upon socially to contribute according to our abilities to common, interpersonal goods. ${ }^{4}$

Normatively, proper respect for each other as reasoning, feeling beings with a capacity for autonomy means respecting that our choices, large and small, gain a significant part of their meaning from our social connections with others, who share in our deliberations, witness our efforts, and often are invested in the results.

Empirically, we face acute psychological and physiological risks when we are deprived of adequate social connections, as we tend to break down mentally, emotionally, and physically when we lack these things. Neurological studies indicate that chronic loneliness, understood as perceived social isolation, generates the same chain of anxiety-inducing physiological threat responses as pain, thirst, hunger or fear. Studies link chronic loneliness with various health risks including high blood pressure, obesity, diminished immunity, depression, alcoholism, reduction in independent living, the progression of Alzheimer's disease, suicide and mortality in older adults. ${ }^{5}$ In the most severe cases, such as coercive isolation in long-term solitary confinement where people are forcibly denied human contact, people tend not only to become despondent and depressed, but also to hallucinate, self-mutilate,

2 J. T. Cacioppo and W. Patrick, Loneliness: Human Nature and the Need for Social Connection (London, 2008).

${ }^{3}$ According to Soran Reader and Gillian Brock, non-contingent needs are the necessary conditions for non-contingent ends that the needing being could not but have. Basic, non-contingent needs pick out the minimal needs for continued survival as the kind of being it is. For example, 'I need water.' 'What for?' 'I can't live without it.' Noncontingent needs are uniquely morally important since 'the very existence of the needing being as we know it is at stake', which makes them grave and urgent moral demands for support. S. Reader and G. Brock, 'Needs, Moral Demands, and Moral Theory', Utilitas 16 (2004), pp. 251-66.

${ }^{4}$ I develop an account of our social contribution needs in 'Social Contribution Injustice', forthcoming in the Proceedings of the Aristotelian Society, Supplementary Volume (2016).

5 Cacioppo and Patrick, Loneliness; J. Decety and J. T. Cacioppo, Handbook of Social Neuroscience (New York, 2011). 
become psychotic and become suicidal, and the residual effects can last long after the isolation ends. ${ }^{6}$

As these points suggest, having adequate access to social connections is not only instrumentally valuable for the development and maintenance of basic cognitive abilities, physical abilities and health, but also valuable in itself. And being deprived or limited in our access to these things is not only instrumentally disvaluable, but disvaluable in itself as the loss of states of being that contribute to a decent human life.

Moreover, these points show that our fundamental interests in social connections are sufficiently weighty, in principle, to ground certain positive social rights. These rights are moral rights, in the first instance, but they also lay the foundation for certain legal rights. These positive social rights include, first, rights to minimally adequate access to the conditions that enable us to cultivate and sustain our social abilities and, second, rights to decent social contact, inclusion and association, if not much more. ${ }^{7}$

Some thinkers might doubt that such interests could ground rights because rights correlate with duties, and positive social duties may seem to be infeasible to the extent that they require affectionate emotions from duty-bearers since emotions cannot be commanded. ${ }^{8}$ This doubt rests on two mistaken assumptions. The first is that our emotions are not sufficiently under our control that they can be commanded. There is considerable psychological and neurological evidence that we can exercise control over our emotions and affections. ${ }^{9}$ The second mistaken assumption is that it is a necessary condition for weighty interests to qualify as rights that they generate only feasible duties. This is mistaken because we can have reasons to do things that we are presently unable to do. Moreover, we can have duties to do things - such as be a good parent - that, typically, we are able to do in any given moment, but that we cannot sustain at all times. In all

${ }^{6}$ A. Gawande, 'Hellhole: The United States Holds Tens of Thousands of Inmates in Long-Term Solitary Confinement. Is This Torture?', New Yorker, 30 March 2009.

${ }^{7}$ For an extended defence of these points, see K. Brownlee, 'A Human Right against Social Deprivation', The Philosophical Quarterly, 63 (2013), pp. 199-222.

${ }^{8}$ I thank an anonymous referee for highlighting this worry.

${ }^{9}$ For a compelling case for the claim that our emotions are sufficiently under our control to be the object of duties, see S. M. Liao, 'The Right of Children to be Loved', The Journal of Political Philosophy 14 (2006), pp. 420-40. This view is corroborated in the psychology and neuroscience literature. See, for example, D. Siegel, Mindsight (Oxford, 2010), and R. Hanson and R. Mendius, Buddha's Brain: The Practical Neuroscience of Happiness, Love, and Wisdom (Oakland, 2009). 
probability, it is infeasible for us to be good parents each and every day that we are parents. ${ }^{10}$

This article explores the tension between our needs for social connections and our need for associative control. Having considerable control over our decisions to associate or not is important for selfrespect, autonomy and well-being. This need is sufficiently weighty to ground certain rights of associative choice. The tension between these rights and positive social rights creates ethical dilemmas that we might call dilemmas of sociability, which throw into sharp relief the clash between our reasons and duties to provide decent social connections to each other and our interests in having considerable say over our associative decisions.

Some particularly pressing dilemmas of sociability are each-we dilemmas of sociability. The tag for each-we dilemmas in general is the familiar Kantian question: 'What if everyone did that?' In Derek Parfit's words, an each-we dilemma arises in cases where:

if each of us rather than none of us does what would be in a certain way better, we would be doing what would be, in this same way, worse. ${ }^{11}$

An each-we dilemma of sociability arises when the associative choices that make our lives go better individually make our lives go worse when all others make the same choices. Some tag questions here are: what if everyone chose not to associate with a given person? Or, what if everyone chose to associate with that person? Or, what if everyone chose not to associate with anyone else? Our ordinary exercises of associative control in excluding and approaching each other become deeply morally problematic when everyone else makes the same choices since it is vital for us both individually and collectively that each person have sufficient access to decent social connections.

To resolve each-we dilemmas of sociability, we must prioritize either negative rights to dissociate or positive rights to social connections. This article shows that we must prioritize positive social rights and, consequently, must actively attend to the distribution of social resources in society. By social resources, I mean, as I explain in section I, (1) our personal abilities to offer social connections to each other, (2) our opportunities to have social connections and (3) our actual social

10 See K. Brownlee, 'Dwelling in Possibility: Ideals, Aspirations, and Human Rights', Human Rights: Moral or Political?, ed. Adam Etinson (Oxford, 2015, forthcoming). Moreover, our rights and, particularly, the voluntary non-assertion of our rights make an important contribution to the conceptual terrain of social connections by helping us to make sense of concepts such as supererogation, generosity and forgiveness. See Brownlee, 'Social Deprivation', and J. Tomasi, 'Individual Rights and Community Virtues', Ethics 101 (1991), pp. 521-36.

11 D. Parfit, On What Matters, vol. 1 (Oxford, 2011), p. 302. 
connections. The priority of rights to social connections has implications both for personal morality and for politics since the regulation of access to social resources is partly a matter of public institutions, a topic that has received little attention in political philosophy. ${ }^{12}$ In regulating access to social resources, we must adopt a sufficientarian approach that best honours fundamental social needs.

\section{EACH-WE DILEMMAS}

Let's begin by reviewing the features of each-we dilemmas in general. The 'What if everyone did that?' question echoes Kant's law of nature formula that it is wrong to act in some way unless we could rationally will it to be true that everyone acts in this way when they can. ${ }^{13}$ Kant's law of nature formula applies best, Parfit says, to acts of which it is true that: (1) it would be possible for many people to act in this way, (2) the effects of each person's act will be similar irrespective of the number of people who act in this way and (3) the effects will be roughly equally distributed among the people involved.

One common type of each-we dilemma, Parfit notes, is the selfbenefiting dilemma (often called the prisoner's dilemma) in which each of us is a member of a group of whom it is true that we could either benefit ourselves or give some greater benefit to others that would be equally distributed among the members of the group, and each of our actions would not have a significant effect on the others' actions. In the classic prisoner's dilemma, our options are (1) to defect (i.e. confess to the crime) while our partner stays silent, in which case we will go free and our partner will get a harsh punishment of ten years in jail, or (2) to remain silent and, provided our partner does the same, both get a modest punishment of six months in jail. If we remain silent and our partner defects, then we get ten years and our partner goes free. And, if we both defect, then we each get a fairly harsh punishment of six years in jail. In short, it is best for us individually if we defect and our partner does not, but it is worst for us both if we each defect than if neither of us defects.

The self-benefiting, prisoner-style dilemma may seem like a loose usage of the term 'dilemma' since in moral philosophy 'dilemmas' are cases of moral conflict where we have two competing moral duties each of which we are able to perform, but not in combination. The

\footnotetext{
12 For a discussion of the distributive justice of relational resources, see C. Cordelli, 'Justice as Fairness and Relational Resources', Journal of Political Philosophy 23 (2015), pp. 86-110. By 'relational resources', Cordelli means something different from what I describe here as 'social resources'. By 'relational resources', she means the by-products of healthy relationships such as trust and self-respect.
}

13 Parfit, What Matters, p. 14. 
prisoner-style dilemma is best seen as a conflict between individual good (narrowly understood) and collective good. Some of the each-we dilemmas of sociability identified below are also best seen as conflicts of values rather than conflicts of duties. There is the value of our making autonomous decisions about our associations, and there is the value of our having our basic social needs met, which if ignored can lead to detrimental results for all. As conflicts of values, these dilemmas are not wedded to Kantian thinking, though they find their inspiration there.

The prisoner-style dilemma is a non-distributive each-we dilemma since there is no limited, divisible good to be distributed among the members of the group. It contrasts with distributive each-we dilemmas, such as Parfit's fisherman's dilemma:

If each fisherman uses a larger net, he will catch more fish, whatever the other fishermen do. But if all of the fishermen use larger nets, the fish stocks will decline so that, before long, they will all catch fewer fish. ${ }^{14}$

To be a dilemma, the fisherman's dilemma relies on a few assumptions. First, it assumes that there are enough fishermen fishing that their fish-taking will deplete the stocks over time and affect each other's ability to catch a given amount of fish. But, of course, this need not be so. If there were only two fishermen in the sea, then neither the largest net that each could construct nor their decision to fish every moment of their waking lives would affect the other's fish-take. As this implies, in distributive cases, the number of parties matters. If that number is small enough relative to the resources, then there is no selfbenefiting dilemma.

Second, the fisherman's dilemma assumes that catching fewer fish is worse rather than neutral or better for each fisherman. But, this need not be so. If the number of fish that each fisherman can catch once every fisherman is using a larger net is still more than she could possibly need or want, then the fact that she can catch fewer than she could if no one (else) used a larger net does not make things worse for her. This point also holds in the absolute terms of 'good' and 'bad' and not just in the relative terms of 'better' and 'worse'. The fact that she can catch fewer fish than she could if others didn't use larger nets is not necessarily bad for her or anyone else. Everyone's using large nets and catching (slightly) fewer fish might still yield an absolutely good fish-take for each. Hence, in the fishermen's case, we must deploy a notion of sufficiency to determine whether a situation in which we all act in a certain way is genuinely worse or genuinely bad for each of us than if none of us acted in that way.

14 Parfit, What Matters, p. 303. 
This article focuses on distributive each-we dilemmas of sociability. These dilemmas arise when we use our social resources in ways that, if everyone does the same, lead to indefensible allocations of social resources. Our social resources include, first, our basic abilities to provide decent contact, society, interaction, communication and association to each other - in short, our abilities to provide social connections - as well as, more richly, our abilities to provide emotional support, responsiveness, empathy, understanding, kindness, compassion, appreciation and love. Second, they include our opportunities to have social connections. Third, they include our actual social connections including our decent interactions, social contacts, acquaintanceships, friendships and loving relationships.

We can use our social resources negatively by withholding them from others, and we can use them positively by providing them to others and, indeed, by seeking them from others. It is part of the nature of social connections that offering social resources and seeking to receive social resources are typically one and the same thing. In light of this reciprocal feature of sociability, it may seem that positive uses of social resources cannot generate each-we dilemmas since the self-benefiting actions of seeking connections and the other-benefiting actions of offering them are typically one and the same thing. ${ }^{15}$ But this thought is mistaken. As we will see, positive uses of social resources can create each-we dilemmas too.

\section{NEGATIVE DILEMMAS}

One dilemma of sociability that comes from our negative use of social resources is captured by a declaration displayed in many US grocery stores and restaurants: 'We reserve the right to refuse service to anyone. ${ }^{16}$ Let's call this the rejected person dilemma:

If Andy shuns Jo, then he will be safe, contented, and well. But, if everyone decides to do the same, then the result is not only bad for Jo, but worse for everyone's safety, contentment and well-being than if no one (or not everyone) shuns Jo. ${ }^{17}$

15 Of course, some people seeking social contact may not be able to give social contact that is decent.

${ }^{16} \mathrm{I}$ am not discussing the associative rights of businesses, private organizations and expressive associations. I use the declaration 'We reserve the right to refuse service to anyone' to capture the kind of each-we dilemma that arises in universalizing a decision not to associate with someone.

17 In negative each-we dilemmas of sociability, the better result for everyone is actually the one in which not everyone avoids Jo, rather than the one in which no one avoids Jo. This is because everyone seeking Jo's company can generate dilemmas of its own, as we will see in section III. I thank Matthew Kramer for pressing me to clarify this point. 
It's better for each 'Andy' individually to shun Jo provided others don't because he then avoids costs to himself, exercises control over the people with whom he associates, and still shares in the avoidance of the bad outcomes that would result from everyone shunning Jo. Moreover, it may be better for each Andy within a small clique to shun Jo provided others outside the clique don't shun her since shunning can strengthen the bonds within the clique, help the members in competitions and enhance their coordination with each other.

Now, the costs of everyone shunning Jo are not evenly distributed across the members of the group since Jo bears the greatest costs in being shunned. Even so, this is an each-we dilemma of sociability because sufficiently grave costs confront all members of the group if they all shun Jo.

First, in shunning Jo, each member loses out on the possibility of benefiting from the social resources that Jo would have contributed ceteris paribus to the collective pool.

Second, each member must bear the risks that go with shunning Jo. Jo's persistent social rejection and chronic loneliness will have substantial negative effects on her that, in an extreme case, include, as noted at the outset, depression, despondency, loss of social ability and personal control, violence, psychosis, suicidal ideation and behaviour, and early death. ${ }^{18}$ Given these effects, the group isolating Jo loses out on Jo's social resources not only at the time she is shunned, but also permanently since the social resources that Jo could have contributed to the collective pool diminish absolutely as a result of her persistent isolation. Indeed, not only does the collective pool of social resources diminish absolutely, but the number of social threats increases absolutely since Jo now poses new, and potentially grave, social threats to the group through anti-social behaviour.

Third, although Jo loses her own social resources, she does not lose her need to receive social resources. She can take, but not give. And, in fact, she needs more social resources post-isolation than she did pre-isolation owing to the debilitating effects of her isolation. Hence, given the threats Jo poses and the resources she needs, it is worse for everyone if everyone shuns Jo than if no one (not everyone) shuns Jo.

Fourth, even if somehow the three above points do not apply in a given case because, for example, Jo is very elderly, nevertheless there are more general costs for everyone in shunning Jo, which lie in the risks for each member that arise from the erosion of group members' attitudes of decency, charity and friendliness and the increase in their

18 See S. Shalev, Sourcebook on Solitary Confinement, Nuffield Foundation Report (2008), <http://www.solitaryconfinement.org/uploads/sourcebook_web.pdf > . 
willingness to let people confront without help not only the awful abyss of loneliness, but also other evils of life.

A variant of the rejected person dilemma is the rejected group dilemma:

If Andy shuns all people like Jo, then he will be safe and contented. But, if everyone in the society who is not like Jo shuns all people like Jo, then over time this will be worse for the safety and contentment of all, and it poses the risk that the pool of available social resources will be smaller than the pool of needed social resources. ${ }^{19}$

Once again, it's better for each individual like Andy to shun all people like Jo, provided that others don't, since he then doesn't bear the costs of associating with such people, exercises control over his associative decisions and shares in the benefits of those people not being universally isolated. Moreover, if Andy is in a small clique, then shunning people like Jo, provided others outside the clique do not, may well further the clique's competitiveness, internal bonding, and coordination.

And, once again, although the people like Jo bear the greatest costs of their being shunned, there are nonetheless sufficiently grave costs for everyone in shunning people like Jo when everyone in the group makes that same choice. This is because the people like Jo will continue to need social resources even though they will have few or none to give. Indeed, each person like Jo will need more social resources than she needed before being isolated because her persistent isolation will render her less able to function independently and seek out social opportunities without assistance. Moreover, even if the number of people like Jo is fewer than the number of people with social resources to give, there may be fewer social resources in the pool than needed owing to the increase in the social needs and decrease in the social resources of the people like Jo.

A further variant of the rejected person dilemma is the rejection of everyone dilemma (or the misanthrope's dilemma):

If Andy shuns everyone, then he will feel safe and contented and won't incur the burdens of interpersonal duties whatever other people do. But, if everyone makes that same misanthropic decision, then the result will be socially worse for all.

The rejection of everyone dilemma dissolves if we make an optimistic, but not unreasonable, assumption that, given differences in people's

19 This dilemma turns on the people like Jo being isolated and unable to secure social connections from each other. 
situations and temperaments, not everyone will seek to do as the misanthrope does. Provided that enough people will continue to seek out the company of others, then, even if everyone who is inclined towards misanthropy were to become a hermit, there would still be enough people who do not seek that lifestyle to constitute a decent society. ${ }^{20}$ That said, this optimistic assumption begins to look naïve if the group we are talking about is a prison population or a closed society whose members have suffered the detrimental effects of social isolation. When enough people lose their capacities to form social connections we cannot assume that it will still be possible to have a decent society.

This point flags the presence of a related problem, which we can call the autonomy dilemma. If we choose to deprive ourselves of social connections by becoming a misanthrope, then we exercise autonomy in a way that can undermine our ability to continue to exercise autonomy because, over time, our social deprivation can undermine our abilities to perceive, assess and function. In this respect, selfdenial of social connections is akin to fasting to the point of starvation: both choices can undermine the practical reasoning abilities that are necessary for autonomy. ${ }^{21}$ And, by rendering ourselves less competent to reason, we render ourselves less able to choose amongst what would otherwise be an adequate range of valuable options. ${ }^{22}$ This autonomy dilemma would be resolvable if acts that undermine the possibility for continued autonomy were not really autonomous, and hence should not be protected as such. But, such a resolution would be ad hoc.

The rejection of everyone dilemma is resolvable as a variant of the egoist's dilemma where a person's options are between acting egoistically or living in a society of egoists. The dilemma is resolvable because the misanthrope, like the egoist, must recognize that she will achieve her aim of acting as she wishes less well when all others act that way too. ${ }^{23}$ If she shuns everyone when everyone else does the same, then she will achieve her aim of solitude less well because collective misanthropy will cause social connections to break down; social chaos, dependency and intrusion will run rampant since acquiring the basic necessities of life takes substantial, coordinated social interaction.

In contrast with the rejection of everyone dilemma, the rejected person and rejected group dilemmas may seem irresolvable since they pertain to our personal freedoms to associate and refuse to associate, and the

\footnotetext{
${ }^{20}$ I thank Jonathan Floyd for highlighting this idea.

21 The conditions for autonomy that I take for granted here are those outlined by J. Raz, The Morality of Freedom (Oxford, 1986), pp. 369-429.

${ }^{22}$ We become like the terrified person trapped in her house trying to escape the murderer, or like the person who is paralysed by a phobia. In such cases, we cannot make use of our options. Our reasoning is diminished such that we cannot decide at all.

${ }^{23}$ Parfit discusses the egoist in What Matters, pp. 15-16.
} 
value of these freedoms for self-respect, autonomy and well-being may seem sufficiently weighty that it couldn't be outweighed by competing positive social rights.

Nevertheless, the rejected person and rejected group dilemmas are resolvable in favour of positive social rights. Before showing this, let me note that specifying the parameters of positive social rights is challenging, and it requires contributions from other fields in addition to philosophy such as medicine, politics, law and economics. In other writing, I propose that we specify our social rights by appealing to a range principle that picks out the relevant range of our basic social needs. Although the contours of people's needs vary, we can identify the range of basic social needs that applies to broadly distinct categories of people. We can distinguish the basic social needs of children from those of people with severe impairments, from those of elderly people, from those of otherwise competent adults. ${ }^{24}$ Our basic social needs are analogous to our basic needs for food and water. Although different categories of people can meet these needs with different amounts and quality of provision, nevertheless those differences will fall within a certain range that can serve to specify the parameters of our rights.

The rejected person and rejected group dilemmas are resolvable in favour of positive social rights most clearly in cases of utter dependency and risk of utter dependency such as babyhood, childhood, acute incapacitation, severe impairment and old age.

First, children have positive claim-rights to a rich set of social connections that goes well beyond merely adequate contact and care from disinterested parties. Children have rights to the kinds of persistent, caring relations of intimate association that are necessary both for their current well-being and for their prospects in the future. And that future necessarily includes both the capacity to make associative choices and the other capacities that depend on that capacity. We all needed someone to associate closely with us when we were children for us to develop the capacities to exercise associative control later in life. Since protection of children's positive social rights is a prerequisite for future associative control, it necessarily trumps others' negative rights to refuse association.

Second, all utterly dependent people have claims of respect, dignity and meaning, which are essentially social properties, and their dependency renders them unable to secure the social connections that would guarantee these things. Respecting each other as reasoning, feeling beings means respecting that the meaning in our lives comes in

${ }^{24}$ See Brownlee, 'Social Deprivation'. 
large part from our social connections especially when we are utterly dependent.

Third, many utterly dependent adults will have made substantial social contributions in the past, and therefore both reciprocity and desert can ground their claim to social connections in the present. ${ }^{25}$

Fourth, utterly dependent adults and children, if not babies, have strong interests in making a social contribution according to their abilities. Since social contribution needs go as much to the heart of our sociality as social access needs do, an inability to offer social resources to others without assistance is analogous in its moral force to utter dependency on others for social access.

The rejected person and rejected group dilemmas are also resolvable in favour of positive social rights when we are at risk of becoming utterly dependent, for reasons similar to those given above. First, having adequate social connections is a precondition not only for the development, but also for the maintenance of our social abilities, and therefore it takes priority over others' negative associative freedom in each-we dilemmas. Second, the arguments about respect, dignity, reciprocity, desert, need, future options and social contribution apply equally to the risk of utter dependency as they do to actual utter dependency.

When we are neither utterly dependent nor at risk of becoming so the rejection dilemmas are resolvable in more subtle ways that secure positive rights to have minimally adequate opportunities to cultivate social connections, but not positive provision of them. However, since chronic rejection can put us at risk of utter dependency, others' freedom to refuse association is checked by the requirement that our minimally adequate social opportunities be meaningful and not render us utterly dependent.

The freedom to refuse association is also checked by the fact that those of us who are not persistently dependent nonetheless face significant moments in our lives that can render us momentarily utterly dependent. ${ }^{26}$ We have strong reasons not to face alone the significant moments of giving birth, facing death and grieving for the loss of a loved one. These great unknowns of life and death can be met with greater equanimity when we have the solace of decent human company. Moreover, in the case of giving birth, there is also the fate of another being at stake.

These conclusions imply a radical truncation of associative freedom, but associative freedom is not nearly as expansive as we tend to

${ }^{25}$ I thank Jonathan Floyd for highlighting this point about past contributions.

${ }^{26}$ I thank David Silver for this observation. 
suppose. ${ }^{27}$ Unlike other personal freedoms such as freedom of religion and freedom of expression, it is necessarily intersubjective. We can practise our religion alone even though religion is a cultural enterprise. And we can express ourselves alone even though typically we aim to use expression to communicate. But we cannot associate alone. Our associative freedom is inextricably bound up with the associative interests of others, and confronts us with an acute form of the Kantian question: what if everyone did that? The default presumption in liberal thinking that we have largely unencumbered associative freedoms must be tempered by an appreciation both of the countervailing positive social rights-claims and of the grave costs for each and for all if people are denied adequate access to social connections.

A critic might agree that we should attend to each person's access to social connections, but deny that this need entail a truncation of individual associative freedom because we can establish appropriate state institutions to meet people's basic social needs. In short, the critic might say that this is a matter of political theory and policy, not a matter of personal morality. I will answer this objection, and explain why social rights are not simply a matter of political theory, after discussing positive each-we dilemmas of sociability.

\section{POSITIVE DILEMMAS}

Positive uses of social resources create each-we dilemmas when everyone in a group puts pressure on the same social resources. There are at least three such dilemmas, which mirror the three rejection dilemmas just discussed. The first is the popular person dilemma, which mirrors the rejected person dilemma:

If Andy seeks out the company of Jo, Andy will be content whatever everyone else does. But, if everyone seeks out the company of Jo, this will be worse for all since Jo cannot provide company to everyone.

In one respect, the popular person dilemma is like the fisherman's dilemma with Jo's social resources standing in for the fish. If too many people put pressure on Jo's society, then there just won't be enough 'fish' to go round. But, the popular person dilemma can be distinguished from the fisherman's dilemma because the apparent scarcity of social resources is due not to an absolute lack of resources, but to people's decision to see the available resources as limited by seeing Jo's social resources as the only ones worth seeking. (It would be like the fishermen

\footnotetext{
${ }^{27}$ For an account of associative freedom as a limited, content-sensitive Hohfeldian permission and claim-right, see K. Brownlee, 'Freedom of Association: It's Not What You Think', Oxford Journal of Legal Studies (2014), doi:10.1093/ojls/gqu018.
} 
deciding that only sea bass is worth catching.) If everyone took a broader view of valuable social resources and distributed their social efforts more equitably, then this distributive each-we dilemma would not arise. In principle, social resources are as plentiful as there are people able to offer them. Each new person joining a group does not increase the pressure on the collective pool of social resources provided that she has social resources to offer and that others in the group are willing to accept her social resources. Unfortunately, we do not always take this view of people's proffered social resources, a fact that indicates that there are good reasons to regulate social connections, perhaps by requiring people to contribute community service in the form of social inclusion service or by nudging people to be more sociable. (I discuss regulation in section IV.)

The second dilemma is the popular group dilemma, which mirrors the rejected group dilemma:

If Andy seeks society from people like Jo, then he will be socially engaged and contented no matter what others do. But, if everyone seeks society from people like Jo, this will be worse for all since people like Jo cannot provide society to everyone.

This scenario doesn't create a dilemma if there are a lot of people like Jo and not many people unlike Jo. It does create a dilemma, though, if the number of people like Jo isn't large enough to meet the social needs of all the people seeking their society. But, like the popular person dilemma, this dilemma is a manufactured one that would dissolve if people were less fussy about their social preferences. The manufactured nature of such dilemmas shouldn't lead us to dismiss them because, as we know, we tend to be clannish creatures who favour cliques, clubs and tribes of us-versus-them through which we shape our identity and sense of security around being exclusive.

The third dilemma is the social butterfly dilemma, which mirrors the rejection of everyone dilemma:

If Andy seeks society from everyone in the group, then he will be socially engaged, secure and happy no matter what others do. But, if everyone seeks society from everyone in the group, then there will be unmanageable pressure on the collective pool of social resources and this will be worse for all than if everyone directed their social energies more fastidiously.

This scenario does not generate a dilemma if all members of the group socialize together: they then just have a big party. But the scenario does generate a dilemma if the social connections everyone seeks and 
offers are two-person interactions. In that case, everyone will put unmanageable pressure on the collective pool of social resources.

That said, the social butterfly dilemma might be partially selfregulating. Although it is true that people only have so much time to give out attention in two-person interactions, it is also true that they only have so much time to receive attention in those interactions. So, they face a choice either to limit the number of people from whom they seek attention or to seek shallow, fleeting attention from a larger number of people. ${ }^{28} \mathrm{It}$ is when conflicts arise between group members' choices that this dilemma remains intact.

This discussion of negative and positive each-we dilemmas of sociability shows that there are significant implications for political theory in attending to the ethics of sociability. In particular, there are strong reasons to care about the distribution of social resources in society. A libertarian, hands-off approach is indefensible since it disregards the fact that social connections are as important as material goods to a minimally decent human life. Despite worries about illiberality, there are strong reasons actively to regulate the distribution of social resources and to favour a sufficientarian approach. Let me flesh out this proposal in more detail.

\section{REGULATION OF SOCIAL RESOURCES}

There are few mechanisms, in western societies at least, to ensure a roughly equal distribution of social resources. We do not place much moral weight on whether one person is highly socially included and another person not at all. But if roughly equal access to decent social connections were necessary for just and fair treatment of people, then an egalitarian principle for distributing opportunities for social connections would be required.

Such a principle could be founded on purely instrumental grounds. We need not entertain the idea that mere equality of social connection is valuable in itself. Even if it were, that value would be outweighed by the gross disvalue of levelling down and rendering everyone, in the name of equality, less socially connected than they need to be. There are instrumental reasons to ensure that enough people do not fall below a baseline of adequate social connection, because, as noted above, if they did fall below it, this would pose risks not only for them but for everyone.

This conclusion invites us to consider the merits of a sufficientarian principle of sociability in contrast with a simply egalitarian one. When we look at our practices we see that we often wholly disregard whether people have sufficient access to decent social connections.

${ }^{28}$ I thank Christopher Bennett for highlighting this point. 
First, although there is modest, growing recognition of the evils of solitary confinement, we still lock up offenders in isolation for long periods, sometimes for over a decade. ${ }^{29}$ Second, we put people in long-term medical quarantine, which may be unavoidable to contain disease, but which tends to result in chronic neglect. ${ }^{30}$ Third, we hold people in isolation for extended periods in immigration detention facilities. ${ }^{31}$ Fourth, we allow vulnerable people such as elderly people, disabled people and immigrants who are not being detained to become chronically acutely lonely. Fifth, we give only a little attention to whether babies and children receive a sufficiently high level of social contact, care and intimate association. Finally, more generally, we adopt individualistic policies that erode the social welfare framework of society. In all of these ways, we show a dismissive attitude towards the fact that people need at least minimally sufficient access to decent social connections regardless of how equally distributed it is above that basic level of sufficiency.

Now, as noted above, a critic might acknowledge that society should attend more actively to people's access to social connections, but argue that this need not imply the regulation of individual associative decisions because we can establish appropriate state institutions to do the job of securing everyone's basic social needs.

In reply, although appropriate state institutions can do a lot, they can never fully guarantee people's social needs. Institutions such as nursing, care-giving and community event organization may well secure access to decent social contact and interaction, but not to sustained social inclusion and intimate association because, first, intimate associations typically are comprehensive, persisting and caring in ways that state-managed provisions tend not to be. This is due partly to the operational realities of state institutions, which prevent the cultivation of persistent, diachronic joint narratives, which are hallmarks of associations. Second, state institutions can only function when there are people willing to assume their offices and perform their duties. ${ }^{32}$ If no one will take on the job of associating with a given person, then that person's social needs go unmet despite the presence of appropriate institutions. This outcome may be no different

${ }^{29}$ Amnesty International USA, 'The Edge of Endurance: Prison Conditions in California's Security Housing Units' (2012), <http://www.amnestyusa.org/sites/default/ files/california_solitary_confinement_report_final.pdf.>

${ }^{30}$ H. T. Stelfox, D. W. Bates and D. A. Redelmeier, 'Safety of Patients Isolated for Infection Control', The Journal of the American Medical Association 290.14 (2003), pp. 1899-1905.

31 The Editorial Board, 'Solitary Isn't the Solution: The Administration Needs Strict Guidelines on Solitary Confinement of Immigration Detainees', Los Angeles Times, 28 March 2013, <http://www.latimes.com/news/opinion/editorials/ la-ed-solitary-confinement-immigrant-detainees-20130328,0,4605341.story> .

${ }^{32}$ I develop this point in Brownlee, 'Freedom of Association'. 
from the outcome in the case where we don't rely on state institutions to secure people's basic social needs and no one will associate with the person. What it shows, though, is that we cannot address the distributive problems of sociability simply by setting up appropriate institutions. The ethics of sociability is, in the first instance, a matter of personal morality. As individuals, we have moral responsibilities to make our social resources available, in principle, to the collective social pool if required, and not to render ourselves socially dysfunctional so as to destroy our potential to make social contributions or unduly to burden the collective pool of social resources. In addition, we have moral responsibilities to acknowledge the social claims that people can have on us not only in virtue of special bonds and legitimate past expectations, but also in virtue of our proximity to them, our awareness of their situation and the relative ease for us of relieving their social suffering. In addition, we have moral responsibilities to concern ourselves with whether other people who are charged with meeting the basic social needs of someone who is utterly dependent are fulfilling that duty properly.

Of course, the state can do a lot to make it easier or harder for us as individuals to offer our care and company to each other. For instance, the state makes it easier when it sets up appropriate venues for ambient sociability, which give us opportunities to engage in our personal activities in close proximity to each other, such as in playgrounds, parks, public squares and even post offices. Such ambient sociability is the cradle for much companionate sociability as we interact and mingle with each other. ${ }^{33}$ Venues for ambient sociability also offer one way to further integration among people from differing walks of life, where integration is understood as the full participation of socially significant groups on terms of equality in all domains of life. ${ }^{34}$ Other ways to further integration include spatial integration of neighbourhoods, housing and schools.

The state also can do a lot to make it easier or harder for us to sustain the social connections we have already forged by attending to such mundane matters as the location of the local hospital, prison and retirement home, the length of standard working hours, the level of maternity and paternity support, and so on. In these and other ways, the politics of recognizing our sociability intersects with personal morality.

Let me finish by noting a difference between social actions and social attitudes. Whereas both negative and positive social actions generate distributive each-we dilemmas as we have seen, only negative social attitudes generate each-we dilemmas. Positive social attitudes do not.

${ }^{33}$ I thank Jeremy Waldron for highlighting this point about ambient sociability.

34 This notion of integration comes from E. Anderson, The Imperative of Integration (Princeton 2010), ch. 6. 
Here is a negative social attitude version of the rejected person dilemma. Let's call it the animosity dilemma:

If Andy hates Jo, and everyone else hates Jo, then, even if Jo is not shunned by everyone, she will experience many of the same detrimental effects of social rejection that she would have felt had everyone shunned her, which will be worse for everyone than if no one hated Jo.

Of course, most likely, Jo has no right not to be hated by a given person (though she may have rights not to be hated universally and not to be hated unjustly). Also, it would be difficult, if not impossible, to subject people's negative attitudes about her to regulation. The point here is that things are worse for everyone if everyone hates Jo than if no one hates Jo.

By contrast, positive social attitudes such as love do not create distributive each-we dilemmas:

If each of us gives love to everyone and seeks love from everyone, it's not the case that there will be an insufficient amount of love to go around.

Love is not like fish. Offering attitudes of love and seeking attitudes of love do not deplete the stocks. Love has a multiplicative effect. As social neuroscientist John T. Cacioppo and his collaborator William Patrick note, well-regulated, socially contented people send social signals that are more harmonious and more in sync with the rest of the environment than do poorly self-regulated, socially disconnected people. Not surprisingly, Cacioppo and Patrick say, the signals that socially contented people receive back are more harmonious and better synchronized as well. 'This rippling back and forth between the individual and others is the corollary to self-regulation that we call coregulation. ${ }^{35}$ A similar thought can be found in Buddhist psychology, which says that there is no necessary limit to the human potential to cultivate loving kindness and compassion.

That said, there is a richer notion of love that requires more than attitudes of loving kindness and friendliness, such as a willingness to do all kinds of things as the occasion arises. This kind of loving takes a lot of energy, and hence offering it and accepting it does deplete the stocks. Love in this richer sense is like fish. ${ }^{36}$

The multiplicative quality of positive social attitudes is significant for both personal morality and regulation. Concerning personal morality, we have good reason to cultivate our social abilities and adopt

35 Cacioppo and Patrick, Loneliness, p. 19.

${ }^{36}$ I thank Daniel Groll for pressing me on this point. 
attitudes of kindness, compassion and warmth towards each person we encounter. Doing so does not put unmanageable pressure on the collective pool of attitudinal social resources. Rather, it enlarges that pool. Concerning regulation, when thinking about how to allocate social resources, we need not worry that there might be problems of nondivisibility or unavoidable scarcity of positive attitudinal goods (even if other problems of direct distribution abound). Such goods are neither non-divisible nor unavoidably scarce.

\section{CONCLUSION}

Let's take stock of the value of social connections. They are intrinsically and instrumentally valuable. They are (1) central to our nature as social creatures, (2) vital for respect for our autonomy, and (3) necessary prerequisites for the development and maintenance of cognitive, physical, emotional and social ability including (4) both the capacity to exercise associative control and the other capacities that depend on it such as respect for others' needs and interests. Consequently, positive protection of social needs must be privileged above associative control when the two conflict.

The duties, values and rights of sociability are fascinating and underexplored topics in moral and political philosophy. Sociability is an unusual domain since the personal honouring and societal regulation of social connections make distinctive moral demands on us. There never was nor could have been an unowned pool of social resources like the unowned land of material goods that existed before people appropriated parts of that natural world and asserted property rights over them. Social resources, by nature, rest with individual persons, and this complicates any effort to honour positive social claims and regulate social resources. Even so, positive social claims put pressure on some of our most complacent liberal assumptions, such as the assumption that we have a largely unencumbered moral right to associate or not with whom we please. These points identify exciting avenues for further reflection within a fully worked out ethics of sociability. ${ }^{37}$

\section{k.brownlee@warwick.ac.uk}

${ }^{37}$ For helpful written comments, I thank Christopher Bennett, Chiara Cordelli, Michelle Dempsey, Jonathan Floyd, Daniel Groll, Robert Jubb, Matthew Kramer, Christoph Ortner, Thomas Parr, Adam Slavny, and two anonymous referees for Utilitas. I also thank Thomas Parr for his research assistance. For useful discussions, I am grateful to audiences at the Warwick Centre for Ethics, Law and Public Affairs research seminar, the University of Reading Ethics and Political Philosophy Launch Conference, the Copenhagen Conference on Applied Philosophy, the Monash Philosophy Seminar and the Association for Legal Philosophy Conference. 